\title{
Effects of levodopa alone and in combination with dopa-decarboxylase inhibitors on plasma renin activity in patients with Parkinson's disease
}

\author{
A.R A P P E L L I, N. G L O R I OSO, R. T E D D E, \\ P. DESSI'- F U L G HERI, A N D F. M O N A CO \\ From the Istituto di Clinica Medica, Cattedra di Patologia Medica II, \\ and Clinica Neurologica, University of Sassari, Sassari, Italy
}

S U M M A R Y Plasma renin activity (PRA) of patients with Parkinson's disease was measured in recumbency, upright position, and after frusemide administration. The results show that the renin responses to both stimuli are significantly reduced as compared with those obtained in a group of normal subjects, while recumbent PRA levels of Parkinsonism patients are not significantly lower than those found in recumbent normal subjects. Levodopa treatment, alone or in combination with two different dopa-decarboxylase inhibitors, benserazide and carbidopa, does not modify the renin response to posture or to frusemide. Although the reduced activity of the renin-angiotensin system can play some role in the genesis of orthostatic hypotensive episodes encountered in patients with Parkinsonism, the greater incidence of orthostatis hypotension in patients treated with levodopa seems to be unrelated to any effect of this drug on the renin release.

Orthostatic hypotension is not uncommon in patients with Parkinson's disease, particularly during levodopa treatment (Keenan, 1970). A reduced activity of the renin-angiotensin system in the genesis of orthostatic hypotension in Parkinsonism patients has been postulated by Barbeau et al. (1969) who found low plasma renin activity (PRA) values in such patients; a further decrease of the renin levels was found during L-dopa treatment.

Low PRA values while recumbent or orthostatic were also found by Michelakis and Robertson (1970) in patients with Parkinson's disease; their orthostatic PRA values, however, rose to normal levels during levodopa treatment. Since L-dopa is a precursor of dopamine and noradrenaline, these authors suggested that L-dopa treatment could possibly enhance the sympathoadrenergic system which plays an important part in the reninreleasing mechanisms.

To elucidate further the behaviour of the reninangiotensin system in Parkinson's disease, and the effects of levodopa on it, we studied the renin

\footnotetext{
Address for reprint requests: Professor A. Rappelli, Cattedra di Patologia Medica II, University of Sassari, Viale S. Pietro, 07100 Sassari, Italy.

Accepted 29 May 1978
}

response to upright posture and sodium depletion before and during treatment with L-dopa alone and in combination with two different dopadecarboxylase inhibitors.

\section{Patients and methods}

Twenty untreated patients with Parkinson's disease were studied. The diagnoses were made on clinical grounds. Hepatic, cardiovascular, and renal disease were excluded by clinical and laboratory investigations. In particular, blood urea nitrogen, creatine clearance, and urinalysis were found to be normal. All patients were put on a normal sodium diet (150 meq/day), and when equilibrium was achieved (on the basis of $\mathrm{Na}$ daily excretion) blood was taken at $08.00 \mathrm{hr}$, after an overnight recumbency, for PRA determination. Blood was taken again after $60 \mathrm{~min}$ of standing upright. During that time the patients were allowed to walk normally in the ward. Then they were made recumbent again and, one hour later, another sample of blood was taken and frusemide $40 \mathrm{mg}$ given intravenously. A final blood sample for PRA determination was taken $45 \mathrm{~min}$ after administration of the diuretic. 
Blood (5 ml) was withdrawn in ice-chilled syringes containing $0.075 \mathrm{ml}$ of a $6 \%$ sodiumEDTA solution and immediately spun down in a refrigerated centrifuge at $1.500 \mathrm{~g}$. Plasma was then separated and kept frozen until the renin assay was carried out. Plasma renin activity was measured in triplicate by angiotensin I radioimmunoassay (Haber et al., 1969).

The patients were then divided at random into three groups corresponding to the following therapeutic regimens: (1) L-dopa alone (Larodopa): six patients (doses from 500 to $3000 \mathrm{mg} /$ day; (2) Ldopa plus benserazide (Madopar): six patients (doses from 500 to $2500 \mathrm{mg} /$ day); (3) L-dopa plus carbidopa (Sinemet): eight patients (doses from 275 to $825 \mathrm{mg} /$ day).

Blood for PRA determination was taken again on the 4th, 7th, 10th, 13th, and 16th day after treatment was begun, both in recumbency and in the upright position. Frusemide administration was repeated on the 4 th and 16th day of treatment. A normal sodium diet (140-160 meq/day) was maintained for the whole period of investigation.

Recumbent, upright, and post-frusemide PRA values obtained in Parkinsonism patients before levodopa treatment were compared with those in a group of 35 normal subjects. The mean age of the patients with Parkinsonism was 57 yr (range 51$72 \mathrm{yr}$ ) whereas the mean age of control subjects was 38 yr (range 24-58 yr). Statistical analysis was carried out using Student's $t$ test between the groups and $t$ test for paired data within the groups.

\section{Results}

As shown in Fig. 1 recumbent PRA (mean \pm SE) of patients with Parkinsonism disease was slightly lower $(1.41 \pm 0.34 \mathrm{ng} / \mathrm{ml} / \mathrm{hr})$ than that of normal subjects $(1.82 \pm 0.18 \mathrm{ng} / \mathrm{ml} / \mathrm{hr})$ but the difference did not reach statistical significance. After the stimulus of standing upright, however, mean PRA values of Parkinsonism patients $(2.33 \pm 0.44 \mathrm{ng} /$ $\mathrm{ml} / \mathrm{hr}$ ) were significantly lower than those obtained in the normal group $(3.48 \pm 0.34 \mathrm{ng} / \mathrm{ml} / \mathrm{hr})$, $(P<0.05)$. The difference between recumbent and upright PRA values in normal subjects was statistically significant $(P<0.001)$ while that found in the patients with Parkinson's disease did not reach statistical significance (Fig. 2). After frusemide administration we observed a similar pattern: from $1.59 \pm 0.21$ to $8.63 \pm 0.48 \mathrm{ng} / \mathrm{ml} / \mathrm{hr}$ of mean PRA in normal subjects $(P<0.0025)$ while in patients with Parkinson's disease the difference between $1.97 \pm 0.66$ and $3.02 \pm 0.92 \mathrm{ng} / \mathrm{ml} / \mathrm{hr}$ was not statistically significant (Fig. 3).

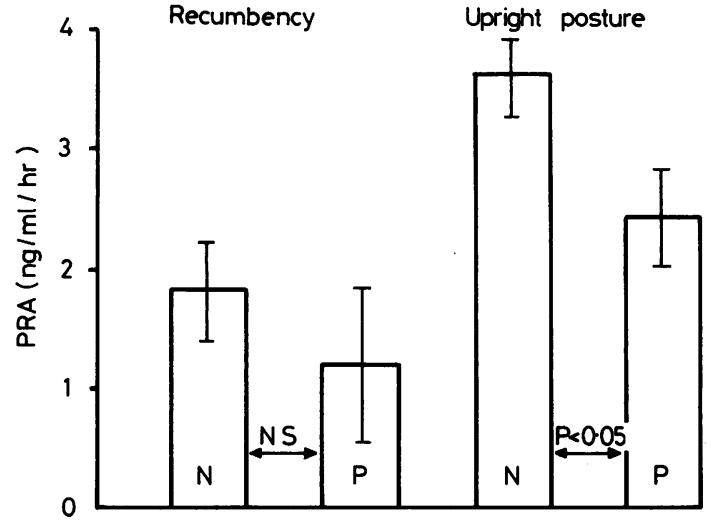

Fig. 1 Comparison between mean ( $\pm S E) P R A$ of untreated Parkinsonism patients and that of normal subjects in recumbency and after one hour in upright position. $N=$ normal subjects, $P=$ patients with Parkinson's disease.

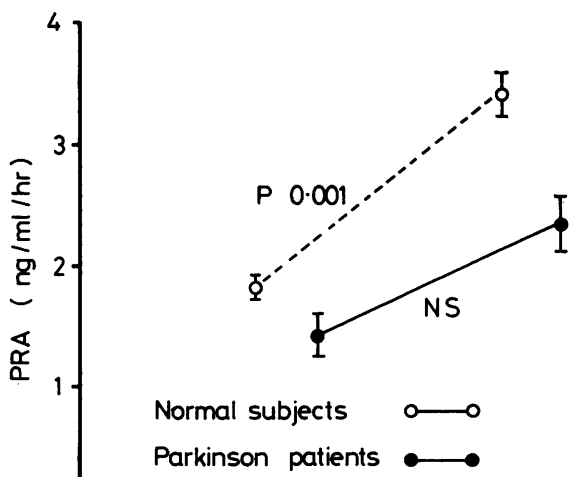

Fig. 2 Postural augmentations (mean $\pm S E$ ) of PRA in normal subjects and in untreated patients with Parkinson's disease.

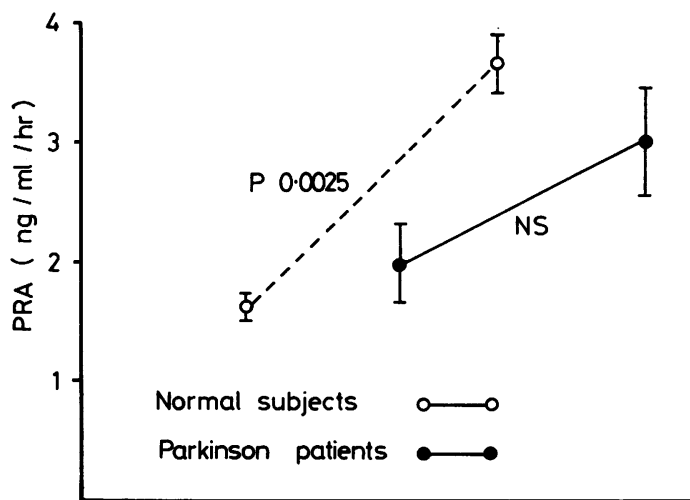

Fig. 3 Effect of intravenous frusemide $(40 \mathrm{mg}$ ) on $P R A$ (mean $\pm S E$ ) of normal subjects and patients with Parkinson's disease. 
The effects of posture and of frusemide administration during treatment with levodopa alone or in combination with benserazide and with carbidopa are summarised in the Table. Considering all patients together the differences between PRA levels in recumbency and those obtained in the upright position as well as after diuretic stimuli were not statistically significant at any stage of levodopa treatment. A similar absence of significant variations in PRA levels after both stimuli was found when the three therapeutic regimens were considered separately.

\section{Discussion}

Our results seem to agree only partially with those reported by Barbeau et al. (1969) and by Michelakis and Robertson (1970). In our cases recumbent PRA levels were not significantly lower than those found in recumbent normal subjects but the renin response after upright and diuretic stimuli appears to be strikingly reduced. This behaviour could be ascribed to a reduced renin storage in the juxtaglomerular apparatus or, more likely, to an impaired sympathoadrenergic stimulation. However, the reduced renin response to both postural and diuretic stimuli found in our Parkinsonism patients before treatment cannot for certain be ascribed to the disease since they were older than the normal control subjects.

As far as the effects of L-dopa on the reninangiotensin system are concerned, our data do not confirm the suppressive action reported by Barbeau et al. (1969) nor the increased renin response to posture reported by Michelakis and Robertson (1970).

It is possible that orthostatic hypotension, which can occur also in patients with untreated Parkinsonism, could be favoured by an inadequate renin release in the upright position. Our data, however, do not support the hypothesis that the greater incidence of postural hypotensive episodes recorded in patients with Parkinson's disease treated with levodopa (Leibowitz and Lieberman, 1975) can be ascribed to an influence of this drug on the renin-releasing mechanisms.

On the other hand, the occurrence of postural episodes also in patients treated with L-dopa in combination with dopa-decarboxylase inhibitors would suggest a central origin of this phenomenon. Some experimental data by Henning and Rubenson (1970) would support this hypothesis.

It is also known that clonidine, a potent hypotensive drug, seems to act through an alphaadrenergic central stimulation (Schmitt et al., 1967), and that the alpha-blocker tolazoline is effective in neutralising the excessive hypotensive effects induced by clonidine overdosage. Furthermore, it has been demonstrated that the local injection of small amounts of noradrenaline in the nucleus of the solitary tract of the rat elicits arterial hypotension and bradycardia (De Jong, 1974). Thus it is not impossible that an increased concentration of dopamine or of its catabolic products or both which can be obtained in the central nuclei after levodopa treatment can induce a similar alpha-adrenergic stimulation, with consequent peripheral vasodilatation and tendency to orthostatic hypotension.

\section{References}

Barbeau, A., Gillo-Joffroy, L., Boucher, R., Nowaczynski, W., and Genest, J. (1969). Reninaldosterone system in Parkinson's disease. Science, 165, 291-292.

De Jong, W. (1974). Noradrenaline: central inhibitory control of blood pressure and heart rate. European Journal of Pharmacology, 29, 179-181.

Haber, E., Koerner, T., Page, L. B., Kliman, B., and Purnode, A. (1969). Application of a radioimmunoassay for angiotensin I to the physiologic measurements of plasma renin activity in normal human

Table Mean ( $\pm S E)$ PRA levels ( $\mathrm{ng} / \mathrm{ml} / \mathrm{hr}$ ) of 20 patients with Parkinson's disease before and during treatment according to treatment group

\begin{tabular}{|c|c|c|c|c|c|c|c|c|}
\hline Treatment group & Number & Bef & ore treatment & Day 4 & Day 7 & Day 10 & Day 13 & Day 16 \\
\hline $\begin{array}{l}\text { All treated } \\
\text { patients }\end{array}$ & 20 & $\begin{array}{l}\mathbf{R} \\
\mathbf{U} \\
\mathbf{F}\end{array}$ & $\begin{array}{l}1.41 \pm 0.34 \\
2.33 \pm 0.44 \\
3.02 \pm 0.92\end{array}$ & $\begin{array}{l}1.74 \pm 0.34 \\
3.16 \pm 0.73 \\
3.42 \pm 0.83\end{array}$ & $\begin{array}{l}1.27 \pm 0.21 \\
3.43 \pm 1.41 \\
-\end{array}$ & $\begin{array}{l}1.13 \pm 0.26 \\
2.59 \pm 0.86 \\
-\end{array}$ & $\begin{array}{l}\text { 1.03. } \pm 0.21 \\
1.78 \pm 0.31 \\
-\end{array}$ & $\begin{array}{l}0.98 \pm 0.19 \\
1.74 \pm 0.32 \\
2.69 \pm 0.93\end{array}$ \\
\hline $\begin{array}{l}\text { Patients treated } \\
\text { with L-dopa alone }\end{array}$ & 6 & $\begin{array}{l}\mathbf{R} \\
\mathbf{U} \\
\mathbf{F}\end{array}$ & $\begin{array}{l}1.31 \pm 0.33 \\
2.31 \pm 0.48 \\
1.47 \pm 0.37\end{array}$ & $\begin{array}{l}1.50 \pm 0.38 \\
2.03 \pm 0.45 \\
2.80 \pm 1.02\end{array}$ & $\begin{array}{l}1.43 \pm 0.35 \\
2.39 \pm 0.83 \\
-\end{array}$ & $\begin{array}{l}1.06 \pm 0.24 \\
1.82 \pm 0.57 \\
-\quad\end{array}$ & $\begin{array}{l}1.51 \pm 0.62 \\
2.25 \pm 0.75 \\
-\end{array}$ & $\begin{array}{l}1.51 \pm 0.41 \\
2.12 \pm 0.65 \\
3.72 \pm 1.87\end{array}$ \\
\hline $\begin{array}{l}\text { Patients treated } \\
\text { with L-dopa } \\
\text { + benserazide }\end{array}$ & 6 & $\begin{array}{l}\mathbf{R} \\
\mathbf{U} \\
\mathbf{F}\end{array}$ & $\begin{array}{l}2.21 \pm 1.05 \\
2.44 \pm 1.04 \\
4.43 \pm 2.26\end{array}$ & $\begin{array}{l}2.04 \pm 1.03 \\
3.75 \pm 1.95 \\
4.38 \pm 1.98\end{array}$ & $\begin{array}{l}1.33 \pm 0.48 \\
6.22 \pm 4.72 \\
-\end{array}$ & $\begin{array}{l}1.60 \pm 0.76 \\
3.69 \pm 2.74 \\
-\end{array}$ & $\begin{array}{l}0.67 \pm 0.17 \\
1.13 \pm 0.44 \\
-\end{array}$ & $\begin{array}{l}0.65 \pm 0.24 \\
1.75 \pm 0.80 \\
2.57 \pm 1.69\end{array}$ \\
\hline $\begin{array}{l}\text { Patients treated } \\
\text { with L-dopa } \\
\text { + carbidopa }\end{array}$ & 8 & $\begin{array}{l}\mathbf{R} \\
\mathbf{U} \\
\mathbf{F}\end{array}$ & $\begin{array}{l}0.89 \pm 0.18 \\
2.26 \pm 0.78 \\
3.20 \pm 1.34\end{array}$ & $\begin{array}{l}1.70 \pm 0.36 \\
3.57 \pm 1.14 \\
3.06 \pm 1.13\end{array}$ & $\begin{array}{l}1.10 \pm 0.33 \\
2.12 \pm 0.76 \\
-\end{array}$ & $\begin{array}{l}0.84 \pm 0.25 \\
2.36 \pm 0.79 \\
-\end{array}$ & $\begin{array}{l}0.94 \pm 0.17 \\
1.92 \pm 0.43 \\
-\end{array}$ & $\begin{array}{l}0.88 \pm 0.27 \\
1.45 \pm 0.31 \\
1.52 \pm 0.56\end{array}$ \\
\hline
\end{tabular}

$R=$ recumbency; $U=$ upright posture; $F=$ after frusemide (40 $\mathrm{mg}$ intravenously). 
subjects. Journal of Clinical Endocrinology and Metabolism, 29, 1349-1355.

Henning, M., and Rubenson, A. (1970). Evidence for a centrally mediated hypotensive effect of L-dopa in the rat. Journal of Pharmacy and Pharmacology, 22, 241-243.

Keenan, R. E. (1970). The Eaton collaborative study of levodopa therapy in Parkinsonism: a summary. Neurology (Minneapolis), 20, 46-59.

Leibowitz, M., and Lieberman, A. (1975). Comparison of dopa-decarboxylase inhibitor (carbidopa) combined with levodopa and levodopa alone on the cardiovascular system of patients with Parkinson's disease. Neurology (Minneapolis), 25, 917-921.

Michelakis, A. M., and Robertson, D. (1970). Plasma renin activity and levodopa in Parkinson's disease. Journal of the American Medical Association, 213, 83-85.

Schmitt, H., Schmitt, H., Boissier, J. R., and Guidicelli, J. F. (1967). Centrally mediated decrease in sympathetic tone induced by 2 (2, 6-dichlorophenylamino)-2-imidazoline (ST 155, Catapresan). European Journal of Pharmacology, 2, 147-148. 